\title{
Social Learning via Improved Daily Writing Assignments, Implementation of Study Groups, and Well-Structured Daily Class Discussions
}

\author{
Shawn R. Tucker, PhD \\ Associate Professor of Fine Arts, Art \& Art History Department \\ Elon University \\ As recent scholarship emphasizes the value of social learning, this article describes a course \\ redesign that sought to encourage such social learning. This multi-year course redesign \\ includes altering a daily writing assignment to make it more specific and to make it a \\ contribution to the learning of a study group. Data was collected and evaluated to explore the \\ effectiveness of this change. The author also offers reflections on how the course redesign \\ encouraged social learning via study groups and how the redesign made daily class \\ discussions more deliberate and robust.
}

In his 2013 book Social: Why Our Brains Are Wired to Connect, Matthew Lieberman discusses the human need for social connection. Lieberman explores the fundamental need that humans have for social connection and how that connection is essential for human development and flourishing. A recent examination in this very journal explores the value of students learning with peers and how to allay fear about social learning that students may have (Jacobs \& Greliche, 2017). With this inspiration, I redesigned elements of my Humanities course to deliberately encourage students to use and value social learning. My course redesign encourages social learning with the implementation of study groups as part of daily classroom activity. The course also uses extra credit on exams to encourage study groups. I also redesigned a daily writing assignment. In fact, the bulk of this article explores that redesign, provides data about it, and discusses the results of the redesign. Finally, the new daily writing assignment provides a more deliberate daily class discussion structure. All three elements are crucial to how the project encourages the social learning that Lieberman recommends so highly.

\section{Background}

I teach an introduction to the Humanities course at a small, private university in the southeastern part of the United States. My course introduces literature, visual art, architecture, music, film, and television arts to about 30 students in each section. The students are mostly first-year students, and the course theme is laughter. To encourage pre-class preparation and reflection, in the fall of 2014 I implemented a daily writing assignment called "The Coolest Thing I Learned." This open-ended assignment invited students to reflect upon the element of the assigned homework that they found most interesting. Students generated a short (350 words) response. Students brought two copies of the response to class. The first copy was turned in, and the second copy was used for small, informal discussions of the material as the class started (see Appendix A for the description of the assigned "The Coolest Thing I Learned" daily paper). 
These assignments encouraged students to come to class prepared, but, as I graded these daily writing assignments, some of them seemed rather superficial. Many responses failed to engage the readings beyond an impressionistic, personal response, and few used evidence from the reading to support their insights. I wondered if the open-ended nature of the assignment contributed to this seeming superficiality. With the help of some ideas from the Teagle-funded Collaborative Humanities Redesign Project team, a team of scholars from several universities involved in course redesign, I decided I would do two things. The first thing was to encourage social learning by putting students into study groups. I hoped that study groups would both encourage the

Many responses failed to engage the readings beyond an impressionistic, personal response, and few used evidence from the reading to support their insights.

value of social learning as well as encourage students to respond with greater insight and substance. The second change was to restructure the daily writing assignment to encourage more specificity and depth.

In order to deliberately encourage social learning, I dedicated a few minutes of the first day of class to putting students into study groups. Each study group had three students. Each student in the study group would have a numerical designation: one student designated as number one, another as number two, and the third as number three. I then changed the daily writing assignment. Instead of having each individual student generate a very open-ended response to "The Coolest Thing I Learned," the revised assignment required students to generate a "Study Group Contribution." The "Study Group Contribution" was the same length as the previous "The Coolest Thing I Learned" assignment, but the difference was that each student in the study group had to respond to a specific prompt as their contribution to the study group's learning (see Appendix B for the description of the assigned "Study Group Contribution" daily writing assignment). I also varied the prompts over the course of the semester so that students would engage different approaches and skills.

An example of the revised assignment is the one I give for John Kennedy Toole's novel A Confederacy of Dunces (see Appendix C). For the new assignment, one student writes about how Toole characterizes the novel's main character, Ignatius, in addition to writing about Ignatius's worldview. A second student has to respond to Boethius's The Consolation of Philosophy and its role in the novel. A third student discusses what the novel says about African-Americans and racism in New Orleans at the time. These specific prompts require that the three members of the study group look carefully at the novel and assemble insights that can be shared with the group. The hypothesis was that this would improve the writing assignments by providing greater focus. This would also encourage study groups, since the class would start with a discussion among study group members about each person's contribution. The third element of this redesign was that then I structured the subsequent class discussion around those three prompts. The prompts are specific enough to generate a focused discussion while still requiring textual analysis skills. The prompts are also well-suited to subsequent class discussion because they not only require students to synthesize many elements of the assignment, but they also allow us to discuss connections between the assigned work and other works examined in the class. 


\section{Effectiveness of Course Redesign}

In order to determine the effectiveness of this change, specifically the change in the redesigned daily writing assignment, I compared the earlier "The Coolest Thing I Learned" papers with the subsequent "Study Group Contributions." I examined the quality of the insights that these papers generated. I had several questions that an analysis of this redesign might answer:

1. Would the open-ended papers generate a broad range of insightful responses or would they yield papers that are vague and superficial?

2. Would the revised assignments, the Study Group Contributions, have the sort of focus that would make them more substantial and insightful compared to the earlier assignments, or would they seem too limited and even mechanical or formulaic?

3. Would the Study Group Contributions give the impression that students are just trying to answer the question without really delving into the assignment with depth or insight?

My focus in comparing the assignments to measure their effectiveness was to see how well students could marshal clear textual evidence to build and support a compelling argument or to support worthwhile insights about the work of art.

In November 2015, I submitted a protocol to the university's IRB to get approval to do this research. I provided the consent form that I would send to students as well as the parameters and the objectives of the research. In December 2015, I was notified that my project had been approved. Each student was subsequently contacted and was given the opportunity to participate or not. An evaluation rubric was developed to examine the daily writing assignments (see Appendix D). This rubric includes three evaluation levels. Papers ranked as "high" use clear textual evidence to build and support a compelling argument. In addition, "high" daily writing assignments demonstrate interesting and thoughtful writing. Assignments judged as "moderate" include some textual evidence to form an argument or provide insight, but the argument and/or the evidence is weaker than papers ranked as "high." "Low" papers have little or no textual evidence and/or fail to make an argument (samples of the levels for both assignments are Appendix E).

\section{Student Work}

The assignments were examined using the rubric, and the results of that examination are in Table 1 on p. 31. The papers from fall 2014 are the "The Coolest Thing I Learned" assignments for the class discussion of A Confederacy of Dunces, while the three subsequent semesters are "Study Group Contribution" assignments for the same reading. The fall, 2014 semester was the first semester I assigned a daily writing paper, so it is the only group of "The Coolest Thing I Learned" assignments that could be compared. 
Table 1

Data from the Evaluation of the Daily Writing Assignments

\begin{tabular}{lcccc}
\hline & Fall 2014 & Winter 2015 & Spring 2015 & Fall 2015 \\
\hline High & 6 & 16 & 17 & 18 \\
Moderate & 9 & 7 & 8 & 10 \\
Low & 11 & 0 & 0 & 0 \\
\hline
\end{tabular}

\section{Reflections}

As these results demonstrate, students produced writing with much more textual evidence and a stronger argument with the revised Study Group Contributions than the earlier "The Coolest Thing I Learned" assignments. This finding confirms that the focused prompt led to writing with stronger evidence and better arguments. It is interesting to note that there were no daily writing assignments assessed as "low" for the Study Group Contributions. Part of what might also accounts for this improvement is that students knew that they were going to have to share their contributions. Students knew that their group was relying upon their input. The collaborative nature may have encouraged everyone to at least produce "moderate" contributions to the study group.

Of the earlier "The Coolest Thing I Learned" papers, the best ones used evidence from the assignment and tended to link a discussion of the assignment with something of interest to the student. Weaker papers featured personal, subjective responses, while the weakest ones spoke almost exclusively about the student's response to reading the novel with little meaningful exploration of the book itself. The best Study Group Contributions provided a thorough response to the prompt, ample textual evidence, and a solid, interesting argument. Even the moderate papers provided a stronger exploration of the book than the correspondingly moderate "The Coolest Thing I Learned" papers. This revision may be particularly useful for first-year students, who may be less comfortable or experienced engaging the assigned work and responding in an analytic instead of an almost exclusively subjective manner.

Where the data offers clear evidence of the effectiveness of this revision in generating student work with stronger textual evidence and better arguments, the course redesign includes two other elements that do not lend themselves to a similar data analysis. These elements are encouraging social learning via study groups and clarifying the structure of daily class discussions. As mentioned - previously, students who knew they were contributing to a study group instead of merely talking about something they found that was "cool" may have benefited from the social pressure and connection to make evidence-based and stronger responses. In addition, with respect to the goal of encouraging social learning, I offered extra credit to students who prepared for their exams by studying with study groups. The extra credit was a modest $2 \%$ bump in the exam score, and I implemented this with the change in the writing assignment in the winter of 2015. Over the subsequent semesters I have consistently had between $50 \%$ and $65 \%$ of students prepare for exams with study groups. While students have taken this option more often than not and while those who do seem both excited and happy with it as well as report a positive experience, I have neither the data 
nor the means to measure exactly how effective study group preparation has been relative to individual preparation. My impression from their enthusiasm for it and their positive experiences with it seem to indicate that it is effective.

In addition to encouraging social learning, the nature of the Study Group Contribution prompts made them excellent points-of-departure for the subsequent class discussion. In fact, with these assignments in place, I structure the subsequent class discussions around those prompts. We spend about one third of the class, to use the example from the class on A Confederacy of Dunces, discussing Ignatius, his character and characterization, his worldview, and his relationships with key characters. We then spend another third of the class discussing The Consolation of Philosophy and how that book provides the structures for both Ignatius' thinking and the novel itself. The final third of the class is spent examining the role of race in the novel. As students had examined these issues before coming to class, they are ready for a lively discussion about these topics. My experience is that these prompts and the format encourage students to study in groups. They also provide a clear structure for class. Lacking any data to substantiate how well this revision clarified daily discussion structure, all I can offer are my impressions, but it does seem that the class discussions are structured in a way that is easy for students to understand and anticipate. Students come much better prepared for those discussions because they have addressed a specific prompt. My impression is also that our class discussions now can focus more on the text, on important issues, and on evidence and arguments related to the assignment rather than subjective responses to the reading. In addition, students seem to appreciate the deliberate structure and respond positively to how well class discussions seem organized. In these respects, the course redesign produced better initial conversations about the assignment, better class discussions of the text, better understanding of the course as a whole, and more robust social learning.

\section{References}

Jacobs, G., \& Greliche, N. (2017). Lieberman, M. (2013). Social: How our Convincing students that their brainsare wired to connect. New York, NY: groupmates' success can increase, not Crown Publishers.

diminish, their own success. InSight: $A$

Journal of Scholarly Teaching, 12, 145-57. 


\author{
Appendices \\ Appendix A \\ Description of “The Coolest Thing I Learn” Daily Writing Assignment
}

\title{
Coolest Thing I Learned (CTIL)
}

In addition to taking the daily quiz, you will also write a 300 word explanation of the coolest thing you learned from that day's assignment. The audience for this short piece is your classmates. You will bring TWO (2) copies of this to class. One copy you will turn in as class starts; the other copy you will use for a short, informal discussion with a classmate or classmates to begin each class. You may be asked to share your CTIL with the entire class. Each CTIL is worth 5 points, and they are graded pass/fail.

\section{Appendix B}

Description of the "Study Group Contribution" Daily Writing Assignment

\section{Study Group Contribution}

$21^{\text {st }}$ century learners often find that learning is more effective when it is social. While many elements of this course are individual, you will also work with a study group. These study groups will be formed on the first day of class. Each member of the study group will be assigned a number. Part of each class period's assignment is a study group contribution. The study group contribution is a written response to the prompt or question listed in the daily assignment. There are three prompts, and those prompts correspond with each member of the study group. If, for example, you are group member number 3, you will create your study group contribution as a response to study group contribution prompt number 3 . 


\section{Appendix C}

Sample "Study Group Contribution" assignment for class on John Kennedy Toole's A Confederacy of Dunces

\section{Study Group Contributions}

1. What is Ignatius like, what does he wear, how does he interpret the world, and how might his approach to his experiences help and not help him?

2. What is Boethius's The Consolation of Philosophy, what is its connection with the "wheel of fortune," and, in the entire course of the novel, how do different characters like Lana, Jones, Mr. and Mrs. Levy, and Ignatius and his mother go up and down on the wheel?

3. What does the book seem to say about the state of African-Americans, how is this obvious in the lives of people like Burma Jones, and what does the book seem to say about people like Lana Lee, Ignatius, Mr. and Mrs. Levy, and Myrna Minkoff's responses to the racism of the time?

Appendix D

Evaluation Rubric for Daily Writing Assignments

What level of art examination skills does the writing convey?

- High: Clear textual evidence is used to build and support a compelling argument or worthwhile insights about the work of art. It is clear from the writing that the student has solid art examination skills. The writing is interesting and thoughtful. It may or may not combine personal insights.

- Moderate: Some textual evidence is used. That evidence is used to form an argument or provide insights, but it may be weaker in its use of evidence than writing at the high level. The paper may also present an argument or insights that are not as strong or compelling as a high example. The paper may rely too much on personal insights or may fail to effectively connect those insights with the text.

- Low: Very little to no textual evidence is used and/or the paper may fail to make an argument or offering interesting insights. The writing may be vague. It may also be so subjective and "impressionistic" that it leads one to question how well the student understood or even examined the work. 
Appendix E

Samples of "The Coolest Thing I Learned" and "Study Group Contributions"

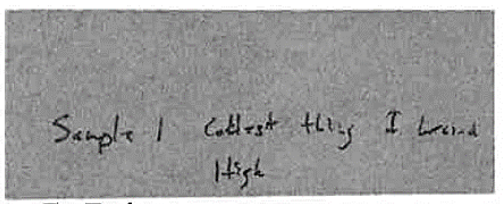

Dr. Tucker

Laughter in the Fine Arts

$10 / 16 / 2014$

$$
\text { CTIL - A Confederacy of Dunces }
$$

After reading the novel "A Confederacy of Dunces" by John Kennedy Toole, I found that the coolest thing I had learned was the genre of the novel of itself. The novel falls under the category of picaresque, a subgenre of prose fiction. The book contains many satirical elements, such as the big picture of Ingatius' ill-minded and lame actions taking a positive effect at the end of the novel, by jailing the unfair and unruly owner of the bar, the Night of Joy, and giving officer Mancuso the glory he has always been in search of. Other effects are caused by his actions, such as the public shaming of Dr. Talc at his school (which is well deserved for his lack of skill in his profession), the liberation of Jones from the bar that he is forced to work at to avoid jailing, the long-deserved retirement of Miss Trixie and her prompt reception of an Easter ham, the better job opportunity given to the B-girl Darlene as an exotic dancer at a finer establishment, and Mr. Levy's avoidance of the lawsuit threatened by one of his vendors. Mr. Levy also receives redemption in his marriage for his good fortune of avoiding the whole situation, and shames his wife for constantly portraying him to be the cause of disgrace in his family to his daughters. He then carries his luck even further by creating a more successful Bermuda shorts company, which then employs Jones. Even Mrs. Reilly gets what she wants, as she is able to start a real relationship with her Claude Robichaux, especially after her decision to commit her son to a mental hospital. It eventually works out for poor Ignatius, as his ex-girlfriend Myrna Minkoff comes and takes him away, instead of to a mental hospital. It was interesting to see this pan out throughout the novel, as it is unclear whether or not Fortuna will grant Ignatius with the good fortune he has been desiring. 


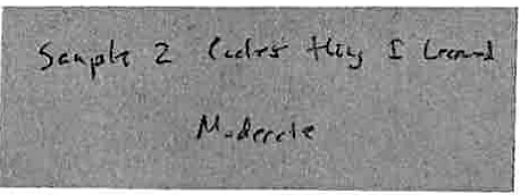

CTIL: A Confederacy of Dunces

First, let me say that I had a difficult time reading and understanding the book. The grammar and vocabulary was difficult for me to read at times and I didn't like nor connect to Ignatius at all. There's only been one other novel where I absolutely couldn't stand any of the characters and A Confederacy of Dunces might place second on that list. I like the themes and meaning of this book, but overall, it wasn't an enjoyable experience for me.

The coolest thing I learned while reading this book however was the argument between fate and free will. This is an argument that isn't frequently discussed, whether humans choices and actions are all set in stone and their life cannot be changed, or if humans have choices in the actions that they make and can constantly change their destiny. I know most people don't believe that our lives are set in stone, but, as a Christian I'm taught that are lives are predetermined. Even though we have the choice to choose, it doesn't affect what happens in the long run because our choices were already planned. Hence, our lives are predestined.

It's interesting to see how this book played with the argument. Ignatius believed that all of his non fortune/fortune occurred because Fortuna spun the wheel and his life ended up being pretty crappy at times. But here, at least to me, Ignatius life doesn't seem predestine. I think he's confused fate and free will, and has blurred the lines because he is always making the choice. And the religious doctrine that he chooses to believe in doesn't set his life in stone, so his life isn't predetermine. However, Fortuna is spinning the wheel so we don't know what will happen to Ignatius (this is what Ignatius thinks). To me fate is somewhat involved, but I don't think his life is solely based on fate, I believe that his life is determine by a lot of his own free will/choices and he covers his mistake by saying it was bound to happen. It's a scapegoat. 


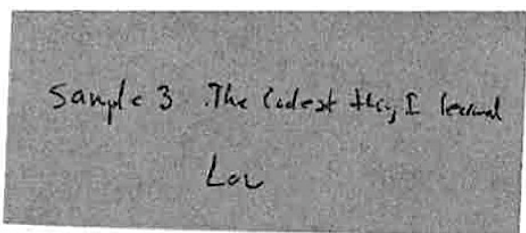

CTIL 11- Confederacy Assignment

After hearing the title of this novel and reading it, I realize I had a very different vision for what the book would be about. I wasn't expecting the drama and plot twists that happened, and I definitely judged a book by its cover/title. I had expected almost a memoir or history book after hearing the Confederacy of Dunces. Therefore, the coolest thing I learned was that this book was not what I had expected and totally took me by surprise. The book changed my perception about what it was going to be, which is very interesting to me.

I also thought the concept of a picaresque novel was very interesting as well. I learned that a picaresque novel is a genre of fiction which can be satirical and depicts the adventures of a mischievous hero of low social class who lives in a corrupt society in a real and humorous way. I thought this was very interesting when comparing a Confederacy of Dunces. I would have never thought Ignatius was a hero throughout the novel, and almost didn't even find him humorous. However, the different jobs including Levy Pants and being a hot dog vendor at Paradise Vendors were funny and entertaining, as were many other scenes in the novel. I thought overall it was an interesting and entertaining novel, and told an important story. 


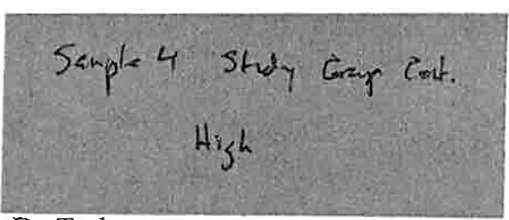

Dr. Tucker

IDS 120

15 October 2015

What does the book seem to say about the state of African-Americans, how is this obvious in the lives of people like Burma Jones, and what does the book seem to say about people like Lana Lee, Ignatius, Mr. and Mrs. Levy, and Myrna Minkoff's responses to the racism of the time?

The book, A Confederacy of Dunces, is set in 1960s New Orleans, a place where racial discrimination was very much prevalent. The Civil Rights movement was on the rise, but discrimination against black people was nowhere near gone. Burma Jones, a black man who is hired at the "Night of Joy" club, is the main African-American character in the book. Jones plays a large role in the story in order to show the state of African-Americans of the time. Although slavery was abolished, Jones character is used to illustrate how black men were still treated as lesser beings. For example, Jones says, about how Lana Lee, "She ain't exactly hire me, She kinda buying me off a auction block" (Toole 34). Lana does not treat Jones very well and, later in the story, she even forces him to dress as a slave for one of her shows. The purpose of this is to show how discrimination was still very present in their society.

The book also incorporates the issue of race in the lives of some of the white characters. For example, it is explained that Myrna Minkoff is involved in Civil Rights activism because she deeply desires to make a difference and save somebody's life. Ignatius, on the other hand, simply wants to "one up" Myrna; therefore, he plans to organize some kind of racial demonstration at Levy Pants, the factory in which he works. In chapter five, Ignatius even compares himself to African-Americans by saying "I have always felt something of a kinship with the colored race, because its position is the same as minc: we both exist outside the inner realm of American society" (144). Although Ignatius does acknowledge that his situation is somewhat "voluntary", he still likens himself to the minority race because he feels like an outsider. 


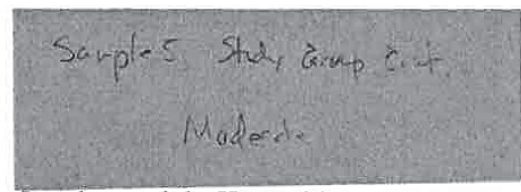

Laughter and the Humanities

Tucker

SGC- Confederacy

$10 / 15 / 15$

What is Ignatius like, what does he wear, how does he interpret the world, and how might his approach to his experiences help and not help him?

Ignatius is an entertaining character to analyze. The large man wears a green hunting cap and carries himself with a false sense of inflated individuality. Overall, Ignatius Reilly might be categorized as a person with a cynical point of view, however, still being convinced that he is better and above everyone. Ignatius' outlook on life forced the character to be wildly selfconfident but in reality, is a lazy unemployable grown child with almost nothing to show for. Along the way, Ignatius' misinformed paradigm has both helped him and hurt him. Positively, the character's enormous ego and out-of-touchness with reality gives Ignatius the confidence to at least attempt to stage a social rebellion, for example. These same qualities work against Ignatius as well. Although he is gifted with self-confidence and a wild imagination, Ignatius doesn't really have any skills besides eating hot dogs and whining. In short, Ignatius' hero is Ignatius, and the character is always high on himself- like when he comes up with the world peace through homosexuality plan. While I can't necessarily dispute his rationale, I don't think it is the most direct path to world peace. Realistically, Ignatius is not an outstanding member of society, but according to him, he is society,

Dr. Shawn Tucker is an Associate Professor of Fine Arts in the Art and Art History department at Elon University. He earned the MA and PhD from Florida State University in Humanities, and $a$ BA in Humanities from Brigham Young University. Since completing the PhD he taught for three years at Northeastern State University in Tahlequah, $O K$, and has been at Elon since 2000. He has published the anthology The Virtues and Vices in the Arts: A Sourcebook (Cascade Book, 2015) as well as Pride and Humility: A New Interdisciplinary Analysis (Palgrave, 2016). His current research focuses on the laughter. 